\author{
удк 342.5 \\ DOI 10.24147/2542-1514.2017.1(1).28-37

\section{ПРАВОПРИМЕНЕНИЕ КАК СПОСОБ ОБЕСПЕЧЕНИЯ НАЛОГОВОЙ БЕЗОПАСНОСТИ ГОСУДАРСТВА}

\author{
К.В. Маслов \\ Омский государственный университет им. Ф.М. Достоевского, г. Омск, Россия
}

\begin{abstract}
Информация о статье
Дата поступления -

02 ноября 2016 г.

Дата принятия в печать -

20 декабря 2016 г.

Дата онлайн-размещения -

20 марта 2017 г.

Ключевые слова

Статья посвящена анализу места правоприменения в системе обеспечения налоговой безопасности государства. Автором проанализированы научные подходы к понятию национальной безопасности как родовому по отношению к налоговой безопасности, выделены его элементы и содержание. В статье предложены авторские понятия национальной безопасности и налоговой безопасности, определены их задачи. Автором описан механизм взаимообусловленности налоговой безопасности государства и правоприменения в налоговых отношениях. Сделан вывод о том, что правоприменение выступает одним из важнейших средств обеспечении налоговой безопасности государства.
\end{abstract}

Налоговая безопасность,

налоговый суверенитет,

правоприменение,

национальная безопасность,

угрозы, методы

\title{
LAW ENFORCEMENT AS A METHOD OF PROVISION FOR NATIONAL TAX SECURITY
}

\author{
Kirill V. Maslov \\ Dostoevsky Omsk State University, Omsk, Russia
}

\section{Article info}

Received - 2016 November 02

Accepted - 2016 December 20

Available online - 2017 March 20

\section{Keywords}

Tax security, tax sovereignty, law enforcement, national security, threats, methods
The place of law enforcement in the system of provision for national tax security is analyzed in the article. The author analyzes scientific approaches to the concept of national security as a generic term to the tax security, highlights its elements and contents.

The author notes that the state, public and personal safety shouldn't be opposed each other, but they should be considered as elements of a unified system of national security Full and effective implementation of the rights and legitimate interests of citizens and their communities equally meets the needs of national security as the protection of the interests of the state as a whole.

The author is convinced that national security and tax security in particular are achievable only in conditions of genuine state sovereignty. The characteristics of the forms of tax sovereignty, as well as classification of threats to tax sovereignty and tax security, are given in the article.

The author's concepts of national security and tax security are given in the article as well as their tasks are defined. National tax security is defined by author as a level of development of public relations in the sphere of taxation, when the amount of collecting taxes corresponds to the number of planned tax revenues taking into account the need for full funding of all functions and tasks of the state and municipalities both in the current period and in the future.

The interests of the tax security, of course, must be taken into account in the enforcement process in tax relations. The author describes the mechanism of the interdependence of the national tax security and law enforcement in tax relations. The ignoring of threats to tax security by tax enforcers reduces the level of security and does not meet the objectives of the implementation of the law in a sovereign state. 
It is concluded that law enforcement is one of the most important methods of provision for national tax security.

Современный этап экономического развития России характеризуется новыми вызовами и угрозами, подрывающими экономическую, а значит, и в целом национальную безопасность страны, что актуализирует проблемы поиска решений, направленных на стабилизацию доходной части бюджетов всех уровней.

Налоги и иные обязательные платежи выступают одним из ключевых источников бюджетных доходов, а в их установлении и взимании проявляется одно из системообразующих, суверенных прав государства [1, с. 99, 107]. «Значительная доля налоговых источников в бюджетах многих стран обусловливает [ключевую] роль налоговых поступлений для стабильного развития экономики и национальной безопасности» [2]. Согласно экспертным оценкам, собственно система налогов в Российской Федерации близка к среднемировым стандартам, в то время как по простоте взаимодействия налогоплательщиков с налоговыми органами (времени, необходимом на изучение и реализацию норм налогового законодательства) наша страна заметно от них отстает ${ }^{1}$. В подобных условиях основным резервом нивелирования налоговых угроз безопасности государства является совершенствование налогового администрирования в целом и налогового правоприменения как его ключевого компонента.

Исследование взаимосвязи между правоприменением и обеспечением налоговой безопасности государства невозможно без выявления существенных признаков данных явлений и формулировки их дефиниций.

Обеспечение безопасности в государстве выступает содержанием разнообразных категорий, близких по природе: государственная безопасность, национальная безопасность, общественная безопасность.

Взгляды исследователей на соотношение указанных категорий значительно разнятся: начиная от отождествления [3, с. 14] и заканчивая разграничением в зависимости от объекта (государства, титульной нации, общества) [4].

\footnotetext{
${ }^{1}$ Paying Taxes 2017. Report by PwC and the World Bank Group. URL: http://www.pwc.com/gx/en/ services/tax/paying-taxes-2017.html (дата обращения: 01.11.2016).
}

В Конституции РФ выделены три основные разновидности безопасности: безопасность государства (ч. 5 ст. 13), безопасность граждан (ч. 1 ст. 56), общественная безопасность (ч. 1 ст. 72).

Наиболее аргументированной, а потому предпочтительной является позиция, представляющая национальную безопасность как родовое понятие, а государственную безопасность, общественную и личную безопасность - как виды, выделенные в зависимости от субъекта, чьи интересы подлежат защите [5].

Национальную безопасность, на наш взгляд, недопустимо понимать в контексте защиты интересов титульной нации, как минимум, потому, что прилагательное «национальный» производно от английского nation, обозначающего не только и не столько нацию (народ), сколько государство.

Исходя из Стратегии национальной безопасности РФ, последняя предполагает защищенность государства, общества и личности в их единстве ${ }^{2}$.

Потому государственную, общественную и личную безопасность необходимо не противопоставлять друг другу, а рассматривать как элементы единой системы национальной безопасности. «Безопасность государства, общества и личности находятся в диалектических системных взаимосвязях и отношениях» [6, с. 67], основанных на единстве и взаимной ответственности [7]. Такой подход предполагает общность на принципиальном уровне интересов и потребностей каждого субъекта безопасности. Потому, например, в процессе государственного строительства недопустимо устранять угрозы государственной безопасности посредством ущемления жизненно важных интересов личности. «Безопасность целостной сложной социальной системы как совокупности взаимосвязанных структурных элементов обусловлена безопасностью её наиболее слабого структурного элемента» [6, с. 67].

То есть полная и эффективная реализация прав и законных интересов граждан и их общностей в равной степени отвечает потребностям национальной безопасности, как и защита интересов государства в целом.

2 Указ Президента РФ от 31 декабря 2015 г. № 683 «О Стратегии национальной безопасности Российской Федерации» // Собрание законодательства Российской Федерации. 2016. № 1 (ч. 2). Ст. 212. 
Национальная безопасность в целом и налоговая безопасность в частности достижимы лишь в условиях подлинного государственного суверенитета.

Исходя из сферы реализации, в структуре государственного суверенитета «можно выделить экономический суверенитет, составной частью которого является суверенитет фискальный» [8]. Категории налогового и фискального суверенитета зачастую используются в качестве синонимов в правоприменительных актах ${ }^{3}$ и юридической литературе [9-11]. С их отождествлением сложно согласиться, поскольку даже этимологически фискальный суверенитет (от fiscus (лат.) - «денежный ящик») относится к взиманию не только налоговых, но любых бюджетных доходов.

Легальное определение налогового суверенитета в российской правовой системе отсутствует. В решениях Конституционного Суда РФ раскрываются лишь отдельные его элементы: признание международным сообществом права государства устанавливать и взимать налоги на его территории ${ }^{4}$ в том числе принудительно, действуя в одностороннем порядке ${ }^{5}$; право государства самостоятельно определять показатели оценки финансово-хозяйственной деятельности налогоплательщика, необходимые для целей налогообложения ${ }^{6}$.

Выступая разновидностью государственного суверенитета, налоговый суверенитет обладает всеми признаками первого применительно к сфере налогообложения. К числу таких атрибутов, как разъяснил Конституционный Суд, следует относить «верховенство, независимость и самостоятельность государственной власти, полноту законодательной, исполнительной и судебной власти государства на его территории и независимость в международном общении» ${ }^{7}$.

В контексте налогового суверенитета верховенство означает способность государственной власти устанавливать и взимать (в том числе с применением легального принуждения) налоги и сборы на

\footnotetext{
${ }^{3}$ Определение Конституционного Суда РФ от 7 декабря 2010 г. № 1572-О-О // Вестник Конституционного Суда РФ. 2011. № 3; Определение Конституционного Суда РФ от 30 сентября 2010 г. № 1258-О-О // СПС «КонсультантПлюс».

4 Постановление Конституционного Суда РФ от 25 июня 2015 г. № 16-П // Вестник Конституционного Суда РФ. 2015. № 5.

5 Постановление Конституционного Суда РФ от 12 октября 1998 г. № 24-П // Вестник Конституцион-
}

ISSN 2542-1514 всей территории страны в отношении любых экономически связанных с ней коллективов и физических лиц, независимо от воли последних.

Независимость государственной власти в сфере налогообложения означает возможность определять и реализовывать налоговую политику, не подчиняясь воздействию иностранных правительств либо отдельных групп налогоплательщиков внутри страны, а действуя исключительно в интересах всего населения государства.

С независимостью тесно связана самостоятельность государственной власти, предполагающая определение любых правил налогообложения волей государства. Данный атрибут показывает, что, вопреки расхожему мнению [11; 12, с. 44], заключение международных договоров, в рамках которых государство принимает на себя обязательства в сфере налогообложения, не ограничивает налоговый суверенитет, а напротив, является одним из способов его реализации. Не исключена возможность денонсации договоров, в случае если они перестанут отвечать интересам государства и начнут создавать угрозу его налоговой безопасности. Международное сотрудничество в сфере правоприменения (обмен налоговой информацией, противодействие налоговым преступлениям, совместная деятельность налоговых служб различных государств) значительно способствует обеспечению налоговой безопасности каждого государства.

В определенной степени ограничивать налоговый суверенитет может существование общепризнанных принципов и норм международного права, действующих на территории страны непосредственно даже в случае их противоречия решениям, принимаемым органами государства. «На содержание налоговых норм все большее влияние оказывает интегрированная международными институтами воля мирового сообщества, существенно ограничивающая фискальный суверенитет и правотворческое усмотрение государств» [13]. Сложно согласиться с М.Ю. Орловым в том, что налоги являются

ного Суда РФ. 1999. № 1; Постановление Конституционного Суда РФ от 17 декабря 1996 г. № 20-П // Вестник Конституционного Суда РФ. 1996. № 5.

${ }^{6}$ Определение Конституционного Суда РФ от 19 мая 2009 г. № 1047-О-О // Вестник Конституционного Суда РФ. 2010. № 1.

7 Постановление Конституционного Суда РФ от 7 июня 2000 г. № 10-П // Собрание законодательства Российской Федерации. 2000. № 25. Ст. 2728. 
ISSN 2542-1514

формой ограничения фискального суверенитета [14, c. 19]. Сами по себе налоги как обязательные платежи выступают проявлением суверенитета государства, ограничивают же его в разумной мере общепризнанные правовые принципы налогообложения. Иллюстрируя такое ограничение, Конституционный Суд РФ отметил, что, хотя законодатель при определении налоговых обязанностей действует в рамках своих дискреционных полномочий, обладая фискальным суверенитетом, налоговое регулирование должно обладать достаточной степенью определенности ${ }^{8}$. Налоговый суверенитет может быть ограничен (но исключительно национальными судебными органами) в той ситуации и в той степени, когда решения законодательных органов в налоговой сфере начинают представлять угрозу налоговой безопасности государства. Так, в п. 4 ст. 2 Общей части Налогового кодекса Республики Беларусь запрещено установление налогов, сборов (пошлин) и льгот по их уплате, наносящих ущерб национальной безопасности Республики Беларусь, ее территориальной целостности, политической и экономической стабильности [15].

Полнота власти означает возможность государства осуществлять законотворчество, государственное управление и правоприменение в налоговых отношениях на всей территории страны без необходимости с кем-либо согласовывать принимаемые решения. Потому трудно признать позицию, согласно которой каждый субъект налоговой политики (включая субъекты федерации и муниципалитеты) могут обладать суверенитетом в пределах ограниченных полномочий [16].

Ученые-конституционалисты выделяют, помимо перечисленных, такой важный признак суверенитета, как единство государственной власти [17, c. 7]. Применительно к сфере налогообложения единство означает системную целостность органов, формирующих и реализующих налоговую политику (Минфин России и подчиненные ему службы). Потому исключительно негативно с точки зрения поддержания налогового суверенитета следует оценивать решение законодателя передать право инициирования уголовного преследования за налоговые преступления из специализированной системы налоговых органов органам следствия. Напротив, с позиций единства государственной власти необходимо рассмотреть вопрос о наделении налоговых

\footnotetext{
${ }^{8}$ Определение Конституционного Суда РФ от 30 сен-
} тября 2010 г. № 1258-О-О // СПС «КонсультантПлюс»; органов полномочиями в сфере оперативно-розыскной деятельности.

Недопустимо сводить реализацию налогового суверенитета лишь к установлению и взиманию налогов.

Внешнее проявление налоговый суверенитет находит в:

1) установлении и введении налогов на территории государства $[14$, с. $19 ; 18$, с. 191$]$, а также в отношении субъектов, экономически связанных с государством;

2) сборе налогов, в том числе их взыскании в одностороннем порядке [19, с. 371], а также в отказе от их взимания (проведении «налоговой амнистии») [20];

3) установлении и реализации механизмов контроля и ответственности в налоговой сфере [21, с. 10];

4) разрешении споров между участниками налоговых отношений [22, с. 11-12].

Таким образом, как сущностные признаки, так и формы реализации налогового суверенитета находятся в системной взаимосвязи. Потому трудно согласиться с мнением о том, что по своей природе налоговый суверенитет является лишь набором фрагментарных принципов, хотя и вошедших в практику государств [23].

Налоговый суверенитет любого государства непрерывно подвергается «испытанию на прочность» со стороны иных субъектов. Угрозы налоговому суверенитету, равно как и налоговой безопасности, в зависимости от источника возникновения могут быть подразделены на публичные (исходящие от органов власти государств и государственно-подобных образований) и частные (источником которых выступают лица, не обладающие публично-правовым статусом).

По территории возникновения можно классифицировать на внутренние и внешние. Внутренние угрозы зарождаются на территории, находящейся под юрисдикцией государства. В их числе, например, попытки регионов нарушить единство налоговой системы страны, вплоть до «налогового сепаратизма» территорий. Источник возникновения внешних угроз находится за пределами территории государства. Это могут быть решения наднациональных образований, членство в которых имеет государство, действия и решения иных государств либо транснациональных корпораций.

Определение Конституционного Суда РФ от 3 февраля 2010 г. № 165-О-О // Вестник Конституционного Суда РФ. 2010. № 4. 
Налоговая конкуренция хотя и может способствовать совершенствованию налоговой системы конкурирующих государств, но в ситуации, когда она связана с предоставлением преимуществ административного характера (в частности, сокрытием информации о бенефициарах бизнеса), представляет серьезный вызов суверенитету и безопасности иных стран.

Значение налогового суверенитета состоит в том, что его наличие дает государству возможность проводить самостоятельную налоговую политику, позволяющую удовлетворять собственные потребности населения, проживающего на территории государства. Потому препятствия в реализации налогового суверенитета в конечном счете угрожают налоговой безопасности государства.

В литературе высказывается мнение о синонимичном значении терминов «экономический суверенитет» и "экономическая безопасность», а значит, и их проявлений в налоговой сфере [24]. Полагаем, что данные понятия не могут являться синонимами.

Обеспечение безопасности людей должно быть единственной целью существования (функционирования) государства, реализации его суверенитета [25, с. 121]. Как следует из классического определения финансовой деятельности государства, она осуществляется «в целях реализации задач социальноэкономического развития, поддержания обороноспособности и безопасности страны» [26, с. 86]. То есть поддержание безопасности является целью и результатом финансовой деятельности государства.

Налог, если рассматривать его с позиций атомистической теории (теории выгоды), представляет собой плату, вносимую каждым за обеспечение его личной и имущественной безопасности, за защиту государства в целом [27]. «Люди соглашаются платить налоги, чтобы таким образом вознаграждать тех, кто оказывает услуги по обеспечению общей безопасности» [28, с. 232].

Своевременное и полное взимание налогов и сборов Конституционным Судом РФ признается условием надлежащего обеспечения функций публичной власти ${ }^{9}$. Как следует из ч. 3 ст. 55 Конституции РФ, установление налогов является разумным ограничением права частной собственности, поскольку это необходимо «в целях защиты основ конституционного строя, нравственности, здоровья,

\footnotetext{
${ }^{9}$ Определение Конституционного Суда РФ от 7 декабря 2010 г. № 1572-О-О // Вестник Конституционного Суда РФ. 2011. № 3.
}

прав и законных интересов других лиц, обеспечения обороны страны и безопасности государства» ${ }^{10}$.

«Обеспечение исполнения налоговых обязанностей - необходимое условие финансовой самостоятельности государства, а следовательно, его экономической безопасности» [29, с. 25]. Из вышеперечисленного следует, что налоговый суверенитет выступает ключевым фактором в обеспечении налоговой безопасности государства.

Определяя термин «налоговая безопасность государства», необходимо исходить из сложившихся в науке подходов к содержанию категорий «безопасности» в целом и «национальной безопасности»:

1. Безопасность как характеристика сложной системы - общества - в ее функционировании и развитии (системный подход) [30, с. 23; 31, с. 109].

2. Безопасность как уровень общественных отношений, обеспечивающий их дальнейшее устойчивое развитие (социологический подход) [32].

3. Безопасность как осознанная потребность субъекта, ценность (аксиологический подход) [33].

4. Безопасность как деятельность субъектов по пресечению угроз (динамический подход) [34, с. 30].

5. Безопасность как состояние защищенности объекта [35], отсутствие опасности [36, с. 88], угроз (статический подход) [37, с. 83].

Именно в таком контексте термины, характеризующие отдельные виды национальной безопасности, классически употребляются как в правовых исследованиях [38; 39, с. 8-9], так и в законодательстве.

В юридическом смысле, учитывая общепринятые подходы к предмету правового регулирования, национальную безопасность необходимо понимать прежде всего как уровень развития общественных отношений в государстве.

Этимологически «безопасность» есть «отсутствие опасности». Потому одной из задач национальной безопасности должна выступать защита общественных отношений от негативного воздействия, угрожающего их существованию.

Второй равновеликой задачей национальной безопасности выступает обеспечение развития общественных отношений согласно выработанным в социуме ценностям. "Феномен безопасности изначально связан не с наличием опасности, а со стремлением субъекта сохранить свое существование, возможность и дальше развиваться в соответствии

10 Постановление Конституционного Суда РФ от 17 декабря 1996 г. № 20-П // Вестник Конституционного Суда РФ. 1996. № 5. 
ISSN 2542-1514

со своей природой» [40]. Сохранение любого явления в динамически изменяющемся мире невозможно без непрерывного совершенствования его ключевых элементов. Обеспечение устойчивого социально-экономического развития обозначено в качестве одной из целей национальной безопасности и в утвержденной Президентом РФ одноименной Стратегии ${ }^{11}$.

Таким образом, национальную безопасность можно определить как такой уровень развития общественных отношений в государстве, при котором обеспечивается как их защита от внутренних и внешних угроз, так и их дальнейшее совершенствование в соответствии с национальными ценностями.

Налоговая безопасность государства в соответствии с приведенным подходом представляет собой такой уровень развития общественных отношений в сфере налогообложения, при котором количество собираемых налогов соответствует количеству, запланированному с учетом необходимости полного финансирования всех функций и задач государства и муниципальных образований как в текущем периоде, так и в перспективе.

Такой уровень достижим только при условии систематической и непрерывной работы всех участников общественных отношений по его обеспечению.

Если рассматривать государственное управление в широком смысле как упорядочивающее воздействие всех органов публичной власти на те или иные сферы общественной жизни [41, с. 118], то следует признать, что осуществление такого управления в правовых формах представляет собой правовое обеспечение.

Правовое обеспечение налоговой безопасности государства может осуществляться путем использования широкого круга методов как нормотворческой, так и правоприменительной природы.
Принятие правоприменительных актов является важнейшим средством реализации органами власти своих полномочий по обеспечению налоговой безопасности, поскольку именно в таких актах реально выражается «принудительность права» [42, c. 144].

«Налоговое правоприменение как форма реализации норм налогового права способствует развитию и охране уже существующих налоговых отношений и формированию новых посредством создания новых юридических фактов, предоставлению субъективных прав и возложению юридических обязанностей на участников налогового процесса, привлечение к налогово-правовой ответственности» [43, c. 21].

Приведенные задачи правоприменения целиком и полностью отвечают целям деятельности по обеспечению налоговой безопасности государства, что позволяет говорить о правоприменении как об одном из ключевых средств обеспечения налоговой безопасности государства.

Правоприменение пронизывает абсолютное большинство управленческих процессов, поскольку отражает пределы самостоятельности субъектов управления, процедуры подготовки и принятия управленческих решений [44, с. 66]. Указанное обстоятельство обусловливает важнейшее значение правоприменительной деятельности для обеспечения налоговой безопасности государства.

Учитывая выявленную суверенную природу налоговой безопасности государства, ее интересы, несомненно, должны учитываться в процессе правоприменения в налоговых отношениях. Игнорирование угроз налоговой безопасности правоприменителями в равной степени снижает уровень ее обеспечения и не отвечает задачам реализации норм права в суверенном государстве.

\section{СПИСОК ЛИТЕРАТУРЫ}

1. Карасева М.В. Финансовое правоотношение / М.В. Карасева. - М.: Норма, 2001. - 288 с.

2. Журавлева О.О. Проблемы унификации подходов к налоговому администрированию / О.О. Журавлева, Л.Ю. Исмаилова // Финансовое право. - 2011. - № 10. - С. 23-26.

3. Редкоус В.М. Административно-правовое обеспечение национальной безопасности в государствах участниках Содружества Независимых Государств: автореф. дис. ... д-ра юрид. наук. / В.М. Редкоус. - М., 2011. $-47 \mathrm{c}$.

4. Кортунов С.В. Концептуальные основы национальной и международной безопасности / С.В. Кортунов. - М.: ГУ-ВШЭ, 2007. - 307 с.

11 Указ Президента РФ от 31 декабря 2015 г. № 683 «О Стратегии национальной безопасности Россий- ской Федерации» // Собрание законодательства Российской Федерации. 2016. № 1 (ч. 2). Ст. 212. 
5. Юрченко М.В. Научно-теоретические основания категории «национальная безопасность России» / М.В. Юрченко, А.В. Давыдов // Вестник Бурятского государственного университета. - 2011. - № 6. - С. 169173.

6. Литвинов Э.П. Философские основы концепции безопасности / Э.П. Литвинов // Пространство и время. - 2012. - № 1(7). - С. 66-73.

7. Башук В.В. Понимание национальной безопасности в философско-правовом и социокультурном аспектах / В.В. Башук // Теория и практика общественного развития. - 2013. - № 9. - С. 350-353.

8. Остроухов Б.А. Международно-правовые проблемы фискального суверенитета государства / Б.А. Остроухов // Юридический мир. - 2009. - № 3. - С. 27-32.

9. Хаванова И.А. Фискальный (налоговый) суверенитет и его границы в интеграционных образованиях / И.А. Хаванова // Журнал российского права. - 2013. - № 11. - С. 41-51.

10. 101 термин налогового права: краткое законодательное и доктринальное толкование / рук. авт. кол. H.А. Соловьева. - M.: Infotropic Media, 2015. - 452 c.

11. Шахмаметьев А.А. Международное налоговое право / А.А. Шахмаметьев. - М.: Международные отношения, 2014. - 824 с.

12. Кривых И.А. Источники налогового права Российской Федерации: понятие, проблемы классификации, основные принципы действия: дис. ... канд. юрид. Наук / И.А. Кривых. - Екатеринбург, 2009. - 284 с.

13. Демин А.В. Принцип определенности налогообложения: монография / А.В. Демин. - М.: Статут, 2015. $-368 c$.

14. Орлов М.Ю. Налог как форма разумного ограничения фискального суверенитета государства / М.Ю. Орлов // Финансовое право. - 2006. - № 2. - С. 18-23.

15. Пилипенко А.А. Экономико-правовые начала формирования налоговой системы / А.А. Пилипенко // Финансовое право. - 2006. - № 10. - С. 21-31.

16. Овчинникова Н.О. Налоговое планирование и налоговый контроль со стороны правоохранительных органов: практическое пособие / Н.О. Овчинникова. - М.: Дашков и К , 2008. - 284 с.

17. Конституционное право: университетский курс: учебник: в 2 т. / под ред. А.И. Казанника, А.Н. Костюкова. - М.: Проспект, 2016. - Т. 2. - 528 с.

18. Кучеров И.И. Теория налогов и сборов (правовые аспекты): монография / И.И. Кучеров. - М., 2009. $473 \mathrm{c}$.

19. Годме П.М. Финансовое право / П.М. Годме. - М.: Прогресс, 1978. - 428 с.

20. Покачалова Е.В. «Налоговая амнистия» в системе финансово-правовых понятий и институтов / Е.В. Покачалова, Т.А. Белова // Налоги. - 2015. - № 2. - С. 28-31.

21. Погорлецкий А.И. Принципы международного налогообложения и международного налогового планирования / А.И. Погорлецкий. - СПб.: Изд-во СПбГУ, 2005. - 388 с.

22. Овсянников С.В. Конституционно-правовые основы налоговых отношений: автореф. дис. ... канд. юрид. наук / С.В. Овсянников. - СПб., 2001. - 41 с.

23. Кудряшова Е.В. Юрисдикция (суверенитет) государств и налоговый иммунитет в области косвенного налогообложения / Е.В. Кудряшова // Финансовое право. - 2005. - № 10. - С. 35-43.

24. Болдырев О.Ю. Вызовы глобализации и проблемы защиты экономического суверенитета государства / О.Ю. Болдырев // Конституционное и муниципальное право. - 2014. - № 5. - С. 71-75.

25. Егоров С.Н. Аксиоматические основы теории права / С.Н. Егоров. - СПб.: Лексикон, 2001. - 272 с.

26. Финансовое право: учебник / отв. ред. Н.И. Химичева. - М.: Инфра-М, 2012. 749 с.

27. Монтескье Ш. О духе законов / Ш. Монтескье // Избранные произведения: в 2 т. - М.: Госполитиздат, 1955. - T. 1. $-800 \mathrm{c}$.

28. Бастиа Ф. Грабеж по закону: пер. с англ. / Ф. Бастиа. - Челябинск: Социум, 2006. - 264 с.

29. Кучеров И.И. Меры налогово-процессуального принуждения: учеб. пособие / И.И. Кучеров, А.И. Кикин. - М.: Юриспруденция, 2011. - 124 с.

30. Степашин С.В. Безопасность человека и общества (политико-правовые вопросы) / С.В. Степашин. СПб., 1994. - 240 с.

31. Поликарпов В.С. Философия безопасности / В.С. Поликарпов. - СПб.; Ростов н/Д.; Таганрог, 2001. $168 \mathrm{c}$. 
ISSN 2542-1514

32. Михалкин Н.В. Безопасность Российской Федерации. Вопросы теории и практики / Н.В. Михалкин. М., 1993. -114 с.

33. Рыбалкин Н.Н. Философия безопасности / Н.Н. Рыбалкин. - М.: МПСИ, 2006. - 296 с.

34. Тимохин П.П. К формированию концепции безопасности России / П.П. Тимохин // Безопасность. 1993. - № 6. - С. 30-56.

35. Тропин С.А. Экономическая безопасность России / С.А. Тропин // Законодательство и экономика. 2004. - № 5. - С. 31-35.

36. Белов П.Г. Системные основы обеспечения национальной безопасности России / П.Г. Белов // Безопасность. - 1994. - № 6. - С. 88-94.

37. Рождественский Ю.В. Безопасность России и словесность (тезисные суждения) / Ю.В. Рождественский // Безопасность. - 1995. - № 3. - С. 83-88.

38. Майоров В.И. Административно-правовые проблемы управления обеспечением безопасности дорожного движения: автореф. дис. ... д-ра юрид. наук / В.И. Майоров. - Екатеринбург, 1997. - 30 с.

39. Сюсюкин А.В. Административно-правовое регулирование экономической безопасности: автореф. дис. ... канд. юрид. наук / А.В. Сюсюкин. - Ростов н/Д., 2004. - 25 с.

40. Гуськов Ю.В. Безопасность: проблемы постижения сущности / Ю.В. Гуськов, Е.П. Резник // Науковедение. - 2013. - № 5. - URL: http://naukovedenie.ru/PDF/23evn513.pdf (дата обращения: 01.11.2016).

41. Старилов Ю.Н. Курс общего административного права: в 3 т. / Ю.Н. Старилов. - М.: Норма, 2002. Т. І: История. Наука. Предмет. Нормы. Субъекты. - 728 с.

42. Алексеев С.С. Социальная ценность права в советском обществе / С.С. Алексеев. - М.: Юридическая литература, 1971. - 224 с.

43. Дементьев И.В. Налоговое правоприменение как форма реализации норм налогового права / И.В. Дементьев // Финансовое право. - 2013. - № 6. - С. 21-24.

44. Кудрявцев В.Н. Право и поведение / В.Н. Кудрявцев. - М.: Юридическая литература, 1988. - 280 с.

\section{REFERENCES}

1. Karaseva M.V. Financial relationship. Moscow, Norma Publ., 2001. 288 p. (In Russ.).

2. Zhuravleva O.O., Ismailova L.Yu. Problems of unification of approaches to tax administration. Finansovoe pravo = Financial Law, 2011, no. 10, pp. 23-26. (In Russ.).

3. Redkous V.M. Administrative-legal provision of national security in the States - participants of Commonwealth of Independent States, Doct. Diss. Thesis. Moscow, 2011. 47 p. (In Russ.).

4. Kortunov S.V. Conceptual fundamentals of national and international security. Moscow, HSE Publ., 2007. 307 p. (In Russ.).

5. Yurchenko M.V., Davydov A.V. The scientific-theoretical bases of a category National safety of Russia. Vestnik Buryatskogo gosudarstvennogo universiteta, 2011, no. 6, pp. 169-173. (In Russ.).

6. Litvinov E.P. Philosophical foundations of the concept of security. Prostranstvo $i$ vremya $=$ Space and Time, 2012, no. 1(7), pp. 66-73. (In Russ.).

7. Bashuk V.V. Interpretation of national security in the philosophical, legal and socio-cultural aspects. Teoriya i praktika obshchestvennogo razvitiya = Theory and Practice of Social Development, 2013, iss. 9, pp. 350-353. (In Russ.).

8. Ostroukhov B.A. International legal and fiscal issues of state sovereignty. Yuridicheskiy mir, 2009, no. 3, pp. 27-32. (In Russ.).

9. Khavanova I.A. Fiscal (Tax) Sovereignty and Its Scope in Integration Bodies. Zhurnal rossiiskogo prava = Journal of Russian Law, 2013, no. 11, pp. 41-51. (In Russ.).

10. Solovyova N.A. (ed.). 101 the term tax law: the legislative and doctrinal interpretation. Moscow, Infotropic Media Publ., 2015. 452 p. (In Russ.).

11. Shakhmametiev A.A. International tax law. Moscow, 2014. 824 p. (In Russ.).

12. Krivykh I.A. Sources of the tax law of the Russian Federation: concept, classification problems, basic principles of action, Cand. Diss. Yekaterinburg, 2009. 284 p. (In Russ.).

13. Demin A.V. The Principle of certainty in taxation. Moscow, Statut Publ., 2015. 368 p. (In Russ.).

14. Orlov M.Yu. Tax as a form of reasonable limit fiscal sovereignty of the state. Finansovoe pravo, 2006, no. 2, pp. 18-23. (In Russ.). 
15. Pilipenko A.A. Economic and legal principles of formation of tax system. Finansovoe pravo, 2006, no. 10, pp. 21-31. (In Russ.).

16. Ovchinnikova N.O. Tax planning and tax control by law enforcement agencies: a Practical guide. Moscow, Dashkov \& Co Publ., 2008. 284 p. (In Russ.).

17. Kazannik A.I., Kostyukov A.N. (eds.). Constitutional law: University course, in 2 volumes. Vol. 2. Moscow, Prospekt Publ., 2016. 528 p. (In Russ.).

18. Kucherov I.I. Theory of taxes and duties (legal aspects). Moscow, 2009. 473 p. (In Russ.).

19. Gaudemet P.M. Financial law. Moscow, 1978. 428 p. (In Russ.).

20. Pokachalova E.V., Belova T.A. "Tax Amnesty" in the system of financial and legal concepts and institutions. Nalogi, 2015, no. 2, pp. 28-31. (In Russ.).

21. Pogorletskiy A.I. Principles of international taxation and international tax planning. St. Petersburg, 2005. 388 p. (In Russ.).

22. Ovsyannikov S.V. Constitutional and legal basis of tax relations, Cand. Diss. Thesis. St. Petersburg, 2001. 41 p. (In Russ.).

23. Kudryashova E.V. Jurisdiction (sovereignty) of States and tax the immune system in indirect taxation. Finansovoe pravo, 2005, no. 10, pp. 35-43. (In Russ.).

24. Boldirev O.Yu. Issues of globalization and security of economical sovereignty of the state. Konstitutsionnoe i munitsipalnoe pravo, 2014, no. 5, pp. 71-75. (In Russ.).

25. Egorov S.N. Axiomatic foundations of the theory of law. St. Petersburg, Leksikon Publ., 2001. 272 p. (In Russ.).

26. Khimicheva N.I. (ed.). Financial law. Moscow, Infra-M Publ., 2012. 749 p. (In Russ.).

27. Montesquieu Ch. On the spirit of laws, in: Selected works, in 2 volumes. Vol. 1. Moscow, Gospolitizdat Publ., 1955. 800 p. (In Russ.).

28. Bastiat F. Robbery by law. Chelyabinsk, Sotsium Publ., 2006. 264 p. (In Russ.).

29. Kucherov I.I., Kikin A.I. Measures of the tax procedural coercion. Moscow, Yurisprudentsiya Publ., 2011. 124 p. (In Russ.).

30. Stepashin S.V. The safety of man and society (political and legal). St. Petersburg, 1994. 240 p. (In Russ.).

31. Polikarpov V.S. Philosophy of security. St. Petersburg, Rostov-on-Don, Taganrog, 2001. 168 p. (In Russ.).

32. Mikhalkin N.V. The security of the Russian Federation. Issues of theory and practice. Moscow, 1993.114 p. (In Russ.).

33. Rybalkin N.N. The philosophy of security. Moscow, MPSU Publ., 2006. 296 p. (In Russ.).

34. Timokhin P.P. Formation of the concept of Russia's security. Bezopasnost', 1993, no. 6, pp. 30-56. (In Russ.).

35. Tropin S.A. Economic security of Russia. Zakonodatelstvo i ekonomika, 2004, no. 5, pp. 31-35. (In Russ.).

36. Belov P.G. Systematic way of ensuring the national security of Russia. Bezopasnost', 1994, no. 6, pp. 8894. (In Russ.).

37. Rozhdestvenskiy Yu.V. Safety of Russia and the literature (abstracts of judgment). Bezopasnost', 1995, no. 3, pp. 83-88. (In Russ.).

38. Mayorov V.I. Administrative-legal problems of management of safety of traffic, Doct. Diss. Thesis. Yekaterinburg, 1997. 30 p. (In Russ.).

39. Syusyukin A.V. Administrative-legal regulation of economic security, Cand. Diss. Thesis. Rostov-on-Don, 2004. 25 p. (In Russ.).

40. Guskov Yu.V., Reznik E.P. Security: the problem of understanding the nature. Naukovedenie, 2013, no. 5. Available at: http://naukovedenie.ru/PDF/23evn513.pdf (date of access 01.11.2016). (In Russ.).

41. Starilov Yu.N. The course of General administrative law, in 3 volumes. Vol. I: History. Science. Object. Norm. Subjects. Moscow, Norma Publ., 2002. 728 p. (In Russ.).

42. Alekseev S.S. Social value of law in Soviet society. Moscow, Yuridicheskaya literatura Publ., 1971. 224 p. (In Russ.).

43. Dementiev I.V. Tax enforcement as a form of realization of the tax law. Finansovoe pravo, 2013, no. 6, pp. 21-24. (In Russ.).

44. Kudryavtsev V.N. Right and behavior. Moscow, Yuridicheskaya literatura Publ., 1988. 280 p. (In Russ.). 
ISSN 2542-1514

\section{ИНФОРМАЦИЯ ОБ АВТОРЕ}

Маслов Кирилл Владиславович - кандидат юридических наук, доцент кафедры государственного и муниципального права

Омский государственный университет

им. Ф.М. Достоевского

644077, Россия, г. Омск, пр. Мира, 55а

e-mail: mas_law@mail.ru

ORCID: orcid.org/0000-0001-8384-277X

ResearcherID: M-6609-2016

SPIN-код: 5325-9716; AuthorID: 678481

\section{БИБЛИОГРАФИЧЕСКОЕ ОПИСАНИЕ СТАТЬИ}

Маслов К.В. Правоприменение как способ обеспечения налоговой безопасности государства /

К.В. Маслов // Правоприменение. - 2017. - Т. 1, № 1. - C. 28-37. - DOI : 10.24147/2542-1514.2017. 1(1).28-37.

\section{INFORMATION ABOUT AUTHOR}

Maslov Kirill V. - PhD in Law, Associate Professor, Department of State and Municipal Law Dostoevsky Omsk State University 55a, Mira pr., Omsk, 644077, Russia e-mail: mas_law@mail.ru ORCID: orcid.org/0000-0001-8384-277X ResearcherID: M-6609-2016 SPIN-code: 5325-9716; AuthorID: 678481

\section{BIBLIOGRAPHIC DESCRIPTION}

Maslov K.V. Law enforcement as a method of provision for national tax security. Pravoprimenenie = Law Enforcement Review, 2017, vol. 1, no. 1, pp. 28-37. DOI: 10.24147/2542-1514.2017.1(1).28-37. (In Russ.). 